\title{
KINE[SIS]TEM'17 From Nature to Architectural Matter International Conference
}

\author{
Maria João de Oliveira ${ }^{1}$ - Vasco Moreira Rato ${ }^{2}$. \\ Carla Leitão ${ }^{3}$
}

\begin{abstract}
With nature as a starting point, KINESISTEM'17 was the first International Conference held in Portugal aiming to share and debate research and design work related to the integration of natural geometries, mechanics and systems fundamentals applied to the scale, function and aesthetics of architecture. Four prominent guest keynote speakers set the pace of the conference: Manuel Kretzer, Alex Haw, Bob Sheil and Alberto Estévez. Gathering academics, students and designers, a significant set of research and practice works was presented and the interplay between diverse scientific fields was also a strong feature at the conference, with attendants coming from areas such as architecture, design, electronics, mechanics, computer science, biology and sociology. This report summarizes the KINE[SIS]TEM'17-From Nature to Architectural Matter International Conference hosted by ISCTE-Instituto Universitário de Lisboa in June 19th-20th, 2017.
\end{abstract}

Keywords Natural geometry · Biomimicry · Biodigital · Parametric design · Performance-based design · Digital fabrication

Maria João de Oliveira

mjoao.oliveira@iscte-iul.pt

Vasco Moreira Rato

vasco.rato@iscte-iul.pt

Carla Leitão

carla@ubiroom.net

1 DINÂMIA'CET-IUL, ISCTE-Instituto Universitário de Lisboa, Lisbon, Portugal

2 ISTAR-IUL, ISCTE-Instituto Universitário de Lisboa, Lisbon, Portugal

3 Rensselaer Polytechnic Institute, Troy, New York, USA

Birkhäuser 


\section{Introduction}

The Anthropocene has been exploring limits between human and non-human existence. In the last 30 years, we have seen nature become a tool, a model and, more recently, a culturally blurred definition.

Anchored in its relationship with inhabitability, architecture evolves criteria as a mediator between environmental concerns, cultural and social forms, material paradigms and innovation, the pleasure of invention and the discovery of new tectonics of articulation.

How can architectural systems moderate synergies between all these factors and attend to the varying expectations of response? This was the starting question for the Kine[SiS]tem'17-From Nature to Architectural Matter International Conference.

Today, the argument for a holistically responsible and relevant architecture requires effective strategies able to respond in a multidimensional way. Challenges ahead require design processes built upon consolidated knowledge, that are able to integrate and co-develop innovative technologies and seek inventiveness in articulation with the so-called natural systems.

\section{The Sessions}

KINE[SIS]TEM'17 comprised 2 days of public presentations, divided into four main sessions. Each session included seven paper presentations and a keynote lecture by one of the four invited speakers: Manuel Kretzer, Professor in the Braunschweig University of Art, Germany, and founder of the 'materiability research network' (http://www.materiability.com); Alex Haw, CEO at the Atmosstudio, UK; Bob Sheil, Director of The Bartlett School of ArchitectureFaculty of the Built Environment, University College London, UK; and Alberto Estévez, Professor at ESARQ, School of Architecture, Director of the Biodigital Architecture Master \& PhD Program and the Genetic Architectures Research Group \& Office at Universitat Internacional de Catalunya (UIC), Spain.

\section{Session 01: The Optimist's Guide to the Anthropocene}

The morning session on day 1 was chaired by Sancho Oliveira (ISCTE-IUL) who highlighted the importance of recent advances in material science, electronics and mechanical systems applied to nature-based architecture, as exemplified by Parlac, who presented several projects based on smart alloys, in which artificial materials were developed to address natural conditions in response to early-stage design requirements. Daguin, Chaltiel and Barney presented several material developments through 3D printing, and Osório discussed the potential of origami-inspired structures and surfaces (Fig. 1). Blonder focused on a straight biomimicry programable recreation of nest structures, and Davidova explored a programable matter-based systemic approach to architectural performance. Closing this first session, Manuel Kretzer (Fig. 2) presented a set of works developed with his 


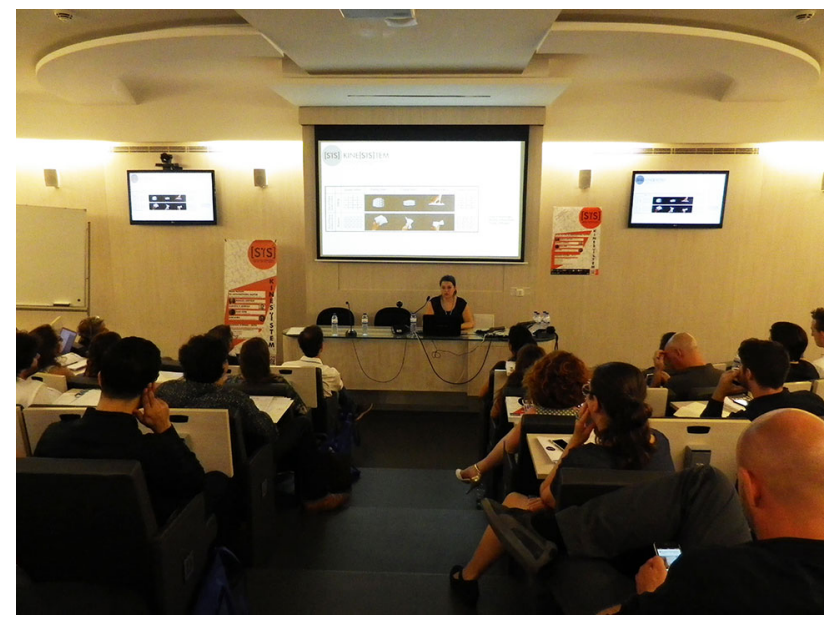

Fig. 1 KINE[SIS]TEM'17-origami folded surfaces: kinetic systems behind the folding presentation

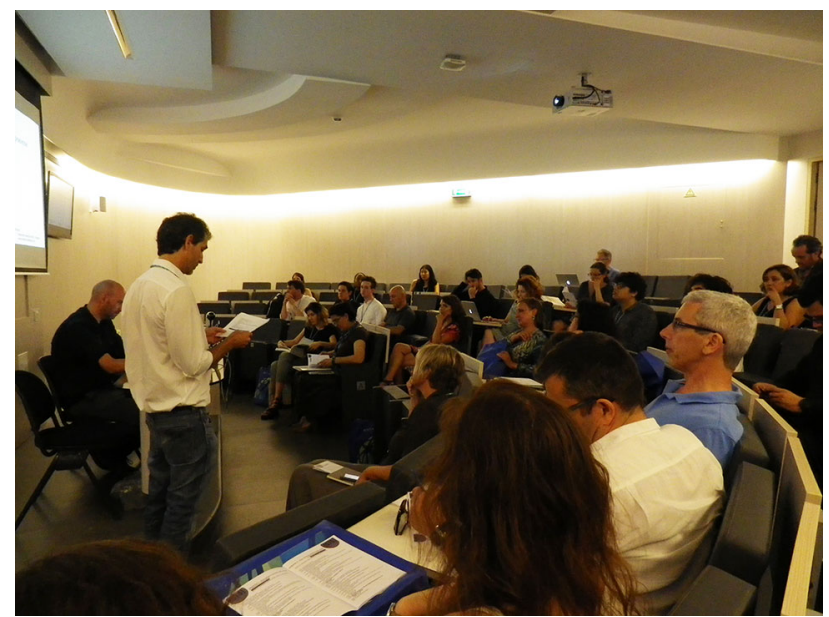

Fig. 2 KINE[SIS]TEM'17-manuel Kretzer session presentation

students, that highlights the importance of a process-oriented design model within the scope of an explorative course. "Even though the presented ideas might seem far from our reality and have various issues that at least for the time being will prevent their practical applicability, we managed to overcome the prevalent course of developing dark and disturbing dystopias, but instead created pleasant and encouraging concepts, which carry seeds of hope and joy" (Kretzer 2017, p. 9).

\section{Session 02: Human Nature}

Day 1 afternoon session, chaired by Carla Leitão (Rensselaer Polytechnic Institute, School of Architecture, NY, USA), featured projects introducing Building 
Information Modeling (BIM) technologies, computational energy efficiency analysis, digital fabrication and social assembly issues. Based on the Psychotropic House by J.G. Ballard, Blanchi and Mortamais presented the paper A psychotropic surface based on soft shape changing material: Emotional input and pneumatically driven actuator, based on their ongoing project that explores data from emotional and sensitive human perceptions as a source for pneumatics systems. This session addressed several subthemes, from Lázaro's research on sustainable road networks, to Rocha's investigations on generative design, Darham's work on energy efficiency and Bulhões's researches on the design for extreme wind conditions. Kozlov brought to discussion the geometric and bionic principles, while Neves demonstrated the rise of the digital fabrication era in a Portuguese context. Alex Haw closed the session presenting the paper Human Nature, denoting that there are "multiple possible definitions of 'human nature' with which we're all familiar with" (Haw 2017, p. 76) and involving the audience on a journey from the matter of language, project environment and construction assemblies to user interaction/ intervention.

\section{Session 03: Digital Doubles, Colliding in Mid-Air}

Day 2 morning session, chaired by Vasco Rato (ISCTE-IUL) led the audience to a bio-inspired journey: from ephemeral installations based on the inherent growth of natural elements for a specific location, to the development of preventive seismic systems based on living organisms. Adaptability in the Built Environment Through the Use of Transformable Architecture, presented by Tsiamis and Haselman, reflected upon the meaning of time in the creation of 'place', assuming that the function of a space is always evolving to adapt its current situation. This third session provided a broad view of different experiences at different scales of intervention-from human seismic controlling presented by Mendez, material performance based-design method by Bedaygi, sunlight studies as an architectural functional decision-making by Saraiva, to kinetic structures by Oliveira and Giodice presentations, that reflected over the human condition at a specific time period existence. Closing this third session, Bob Sheil presented research work carried out at ScanLab, The Bartlett School of Architecture, pointing to time as a measurement unit for space perception: "scales of time and experience are now inextricably mingled, each performance taking place in its present physical space as well as interacting with the previously and presently recorded and soon-to-be represented space." (Sheil and Pearce 2017, pp. 161-162).

\section{Session 04: Metabolic Architecture: Genetics, Digital Morphology, Turing and Artificial Intelligence}

The last session, chaired by João Pedro Xavier (University of Porto) built the way to a reflection about the intensive study of natural elements, biological observation, formal, structural and mechanical growth, and the relevance of these research topics and methods in the academic environment. In this matter, the paper Growth as the Morphological Generator of Biological Identity of Ricardo Massena Gago argues 
that mechanical systems are composed by a set of biological geometries responsible for a more natural integration of forms in a given environment. The implementation of digital fabrication tools is spreading throughout the academic environment of schools of architecture, not only as a valuable method and design process-as Youssef proved-but also through the integration of areas such as material engineering, microbiology and nature geometry studies as Zavoleas, Cardoso and Elbasdi demonstrated. Implications of change and adaptability were stated as main conditions of our time as the audience was invited to speculate about our contemporaneous human condition, through the presentations of Dickinson and Soeiro (Fig. 3).

Closing the KINE[SIS]TEM'17, Alberto Estévez (Fig. 4) addressed the importance of the study of biology and genetics as a keygen for the future of the architectural design processes, revealing work carried out by his master students. "Pedagogically, the sourcing of biological attributes through scientific equipment, genetics, and computational programming serves to technologically open pathways by which emergent intelligent architectures may inhabit nature and partner with biological life" (Dollens and Estévez 2017, p. 254)

\section{Conclusions}

Few projects achieved, until today, the plenitude of a natural system. Man-made creations always reveal assembly weaknesses, formal and structural dissociations, and romantic aesthetic visions as the result of human nature.

The conference exposed a set of academic and professional efforts aiming for a better understanding of the relationship between nature and human habitats.

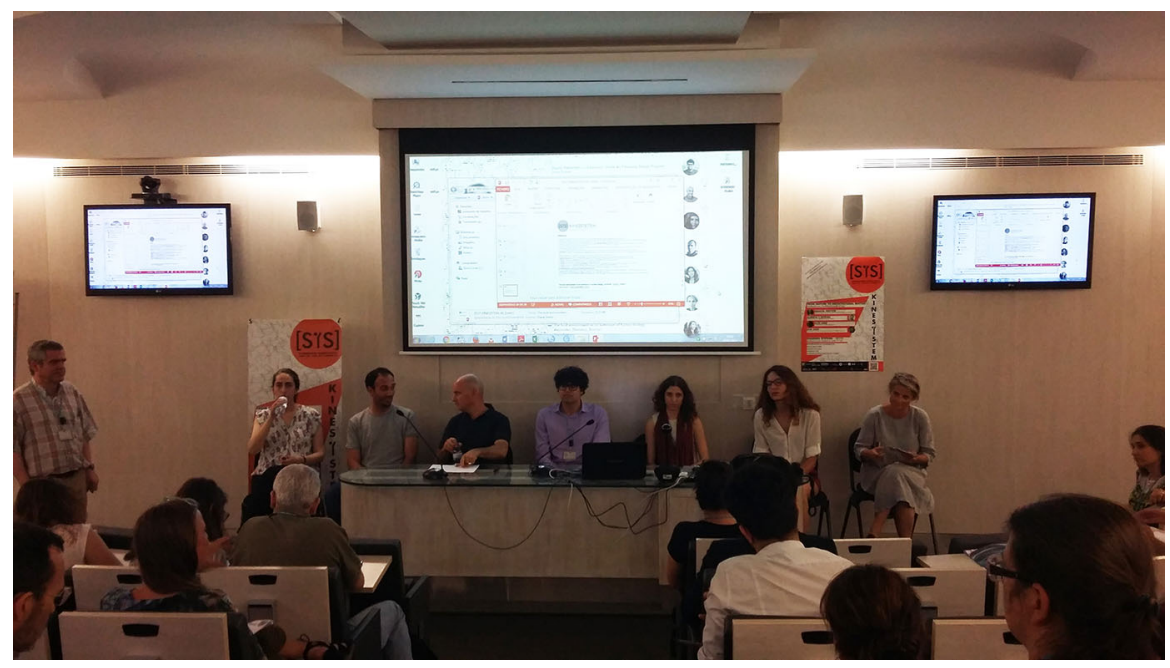

Fig. 3 KINE[SIS]TEM'17-session 4 discussion panel 


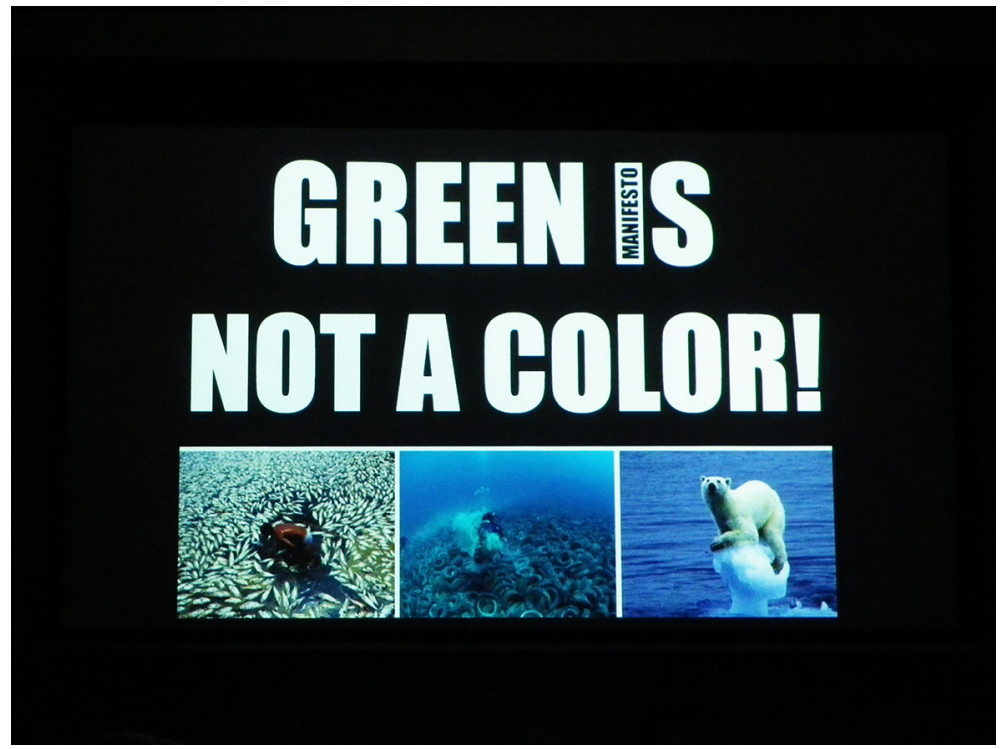

Fig. 4 KINE[SIS]TEM'17-slide from Alberto Estévez's session presentation

KINESISTEM'17 provided a work frame to understand the actual state of affairs regarding the materialization of nature-inspired architecture, laying the basis of future work, considering natural complex systems as infinite inspiration to address physical, formal and aesthetical dilemmas.

\section{References}

Dollens, Dennis L, e Alberto T. Estévez. 2017. "Metabolic Architecture: Genetics, Digital Morphology, Turing, \& AI." Kine[SIS]tem From Nature to Architectural Matter International Conference. Lisbon: DINÂMIA'CET-IUL. 248-256. https://repositorio.iscte-iul.pt/handle/10071/13603. Accessed 23 Feb 2018.

Haw, Alex. 2017. "Human Nature." Editado por Maria João de Oliveira e Filipa Crespo Osório. Kine[SIS]tem From Nature to Architectural Matter International Conference. Lisbon: DINÂMIA'CET-IUL. 76-82. https://repositorio.iscte-iul.pt/handle/10071/13603. Accessed 23 Feb 2018.

Kretzer, Manuel. 2017. "The Optimist's Guide to the Anthropocene.” Editado por Maria João de Oliveira e Filipa Crespo Osório. Kine[SIS]tem From Nature to Architectural Matter International Conference. Lisbon: Dinamia'Cet-IUL. 2-9. https://repositorio.iscte-iul.pt/handle/10071/13603. Accessed 23 Feb 2018.

Sheil, Bob, e Thomas Pearce. 2017. "Digital Doubles, Colliding In Mid-Air.” Editado por Maria João de Oliveira e Filipa Crespo Osório. Kine[SIS]tem From Nature to Architectural Matter International Conference. Lisbon: DINÂMIA'CET-IUL. 150-162. https://repositorio.iscte-iul.pt/handle/10071/ 13603. Accessed 23 Feb 2018. 
Maria João de Oliveira $\mathrm{PhD}$ student in Architecture at Dinâmia'CET-IUL, Institute University of Lisbon (ISCTE-IUL). Master in Architecture and Urbanism at ISCTE-IUL. Postgraduated in Digital Architecture by the Advanced Studies Course in Digital Architecture of ISCTE-IUL/FAUP, with an Amorim Isolamentos scholarship. Researcher at Dinâmia'CET-IUL and VitruviusFabLab-IUL. Her interests focus at developing automated design and construction models, innovative materials applications, modular and interactive physical systems, and social and participatory methods for technology development. She works and publishes in Biodigital Applications in Architecture, Digital Fabrication, and Open Hardware.

Vasco Moreira Rato Vasco Moreira Rato is an Assistant Professor at the Department of Architecture and Urbanism, ISCTE-University Institute of Lisbon, coordinating the scientific area of architecture and building technology, and researcher at ISTAR-IUL and VitruviusFabLab-IUL. He holds a degree in Architecture, MSc in Construction and PhD. in Civil Engineering (Rehabilitation of the Built Heritage). $\mathrm{He}$ has academic and corporate professional experience in materials for architecture and buildings renovation, project management, construction technology, and energy efficiency in buildings. Currently, he develops teaching and research activities related to sustainability, energy efficiency, and materials in architecture.

Carla Leitão Carla Leitao is an architect and writer that lives and works in New York, USA, and Lisbon, Portugal. She is the co-founder, with Ed Keller, of AUM Studio in NY and Umasideia in Lisbon. She has taught architecture studios and seminars in UPenn, Philadelphia, Pratt Institute, Cornell University, and City College, NY and also co-taught at Columbia University, NY. Practice and academic endeavors focus on convergences of Urban Phenomena, Ubiquitous Cultures, Digital Communication, and generation of political and cultural innovation. Publications include "4 Lines" (Akademie Schloss Solitude) and "City Fragments" (CBA). Projects include built and ongoing residential and institutional projects. Exhibitions and installations include "Suture" (SCI Arc and Tellic Gallery, LA) and "True Romance" (Sttuttgart, Germany) and Young Blood in Lisbon, Portugal.

Website: www.aumstudio.org 